\title{
Achalasia case detected during endoscopy application accompanied by anaesthesia
}

\author{
Recai Dağlı', Hakan Bayır², Bilal Ergül${ }^{3}$, Nazan Kocaoğlu ${ }^{1}$, Zeynel Abidin Erbesler ${ }^{1}$ \\ ${ }^{1}$ Department of Anaesthesiology and Reanimation, Faculty of Medicine, Ahi Evran University, Kirsehir, Turkey \\ ${ }^{2}$ Department of Anaesthesiology and Reanimation, Medical School, Abant Izzet Baysal University, Bolu, Turkey \\ ${ }^{3}$ Department of Gastroenterology, Ahi Evran University Teaching and Research Hospital, Kirsehir, Turkey
}

Address for correspondence: Assist. Prof. Dr. Recai Dagli, Department of Anaesthesiology and Reanimation, Faculty of Medicine, Ahi Evran University, Kirsehir, Turkey, phone: +90 5426536975, e-mail: drresel@gmail.com

Achalasia is an uncommon dysfunctional neuromuscular disease of the oesophagus. General anaesthesia might be required for its diagnosis and treatment. During the anaesthesia, complications such as oesophagus dilatation-perforation and tracheal aspiration in oesophagus content might be seen. In order to ensure the security of the respiratory tract, rapid intubation might be required [1]. When anaesthesia is required in endoscopy units for diagnosis, equipment and devices standardised for outpatient anaesthesia applications by American Society of Anaesthesiologists (ASA) should immediately be ready [2].

A 41-year-old male patient, who applied to the Gastroenterology Polyclinic due to gastric complaints and had lymphadenopathy detected in his abdomen ultrasonography, was scheduled for conscious endoscopy. He was unable to tolerate the endoscopy which was applied following twelve-hour fasting, and he vomited. Endoscopy with anaesthesia was then planned, rescheduled with two weeks of strict liquid food diet and pineapple juice application. The patient was taken to the endoscopy unit following $24 \mathrm{~h}$ of fasting, and was monitored with ECG and pulse oximeter. Intubation was then planned. Anaesthesia induction was conducted with $50 \mathrm{mg}$ of remifentanil and $100 \mathrm{mg}$ of propofol. While $\mathrm{O}_{2}$ was provided with a mask, the intraoral and oropharyngeal area was filled with liquid. Despite rapid aspiration, the contents continuously flowed to intraoral area, and the patient's saturation dropped. He was immediately intubated. In the meantime, the amount of aspired liquid content was $900 \mathrm{ml}$. Having reached normal levels of saturation and haemodynamic values in the patient, endoscopy operation began with propofol addition. Significant achalasia and duodenal ulcers were detected. When the patient's respiration was sufficient, he was extubated. The patient, who did not have respiratory problems and whose haemodynamics were stable, was sent to the service without a problem upon observation at the patient recovery room.

In outpatient anaesthesia applications, various mortality rates and complications have been reported. During operation, complications may occur such as; allergic reactions, nausea-vomiting, aspiration of the gastric content, and damaging of the team according to the environment with hypovolaemia. It has been reported that respiratory problems have been encountered in old patients the most, and complications have been encountered mostly in the gastroenterology unit [3].

One of the factors that increases mortality and morbidity during anaesthesia applications is gastric content aspiration. In ASA guides, it has been deemed suitable for adult patients to apply $6 \mathrm{~h}$ of fasting after $2 \mathrm{~h}$ of clear liquid consumption, following light food consumption [4].

Our patient applied 2 weeks of a strict liquid and pineapple juice diet, and he had $24 \mathrm{~h}$ of fasting. However, despite this preparation, high amounts of oesophageal content were encountered. The anaesthesia team, working in coordination, prevented the tracheal aspiration of oesophageal content with a working aspiration system and rapid intubation.

Achalasia is an uncommon disease developing due to neuromuscular dysfunction of the oesophagus. The frequency of the disease, the etymology of which cannot be known precisely, is 1-6/100000. Frequently, male and female rates are equal among patients aged between 25 and 60 years. The oesophagus is characterised by the delay of foods while passing to the stomach and expanding in the oesophagus due to sub three sphincter dysfunction. In patients, respiratory diseas- 
es due to tracheal aspiration depending on reflux and weight lost due to the vomiting of the foods can be seen [1]. Anaesthesia application might be necessary during surgical and endoscopic treatments to be applied for achalasia. Oesophagus dilatation-perforation, which can be seen during general anaesthesia, should be taken into account due to the tracheal aspiration of the food content. In the case of our patient, due to the sub oesophagus sphincter being completely dysfunctional, and despite the long term of fasting, high amounts of food contents collected in the oesophagus.

In the study of Rex et al. [5], although it was stated that during endoscopy, the application of propofol by a team outside of anaesthesia is secure and economical, as it has been in our case, in order to secure the respiratory tracts of the patients, intubation and even resuscitation for other complications might be required. In a published guide [6] it is stated that during endoscopy applications propofol can be used by educated nurses outside of the anaesthesia team for conscious sedation and deep sedation; however, the pre-assessment of the patient should be carried out cautiously, and the nurses should be educated with basic and advanced life support skills.

In conclusion, in patients like ours, whose pre-anaesthesia assessment is normal, occlusion in the respiratory tract that might occur during sedation applications may result in death. We believe that, although uncommon, for outpatient operations these kinds of patients should be sedated and anesthetised by a team composed of anaesthesia experts and technicians in environments with standard equipment conditions and under close follow-up.

\section{Conflict of interest}

The authors declare no conflict of interest.

\section{References}

1. Heitmiller RF, Buzdon MM. Surgery for achalasia and other motility disorders. In: Mastery of Cardiothoracic Surgery. 2nd edition. Kaiser LR, Kron IL, Spray TL (eds). Lippincott Williams \& Wilkins, Philadelphia 2007; 163-73.

2. ASA guidelines for nonoperating room anesthetizing locations. (Available at:) http://www.asahq.org/publicationsAndServices/ standards/14.pdf. (Accessed August 27, 2008).

3. Thompson A, Wright D, Murray W, et al. Analysis of 153 deaths after upper gastrointestinal endoscopy: room for improvement? Surg Endosc 2004; 18: 22-5.

4. Practice Guidelines for Preoperative Fasting and the Use of Pharmacologic Agents to Reduce the Risk of Pulmonary Aspiration: Application to Healthy Patients Undergoing Elective Procedures; An Updated Report by the American Society of Anesthesiologists Committee on Standards and Practice Parameters. Anesthesiology 2011; 114: 495-511.
5. Rex DK, Heuss LT, Walker JA, et al. Trained registered nurses/ endoscopy teams can administer propofol safely for endoscopy. Gastroenterology 2005; 129: 1384-91.

6. Dumonceau JM, Riphaus A, Aparicio J, et al. European Society of Gastrointestinal Endoscopy, European Society of Gastroenterology and Endoscopy Nurses and Associates, and the European Society of Anaesthesiology Guideline: non-anaesthesiologist administration of propofol for Gl endoscopy. Eur J Anaesthesiol 2010; 27: 1016-30.

Received: 20.11.2015

Accepted: 11.01.2016 